\title{
KONSEP INTERIOR RUANG FISIOTERAPI ANAK BERKEBUTUHAN KHUSUS PADA KLINIK ANAK USIA 1-5 TAHUN
}

\author{
Fakhrisa Nur Paramarta \\ Design Interior, Faculty of Creative Industries, Telkom University of Bandung \\ Email: fakhrisa.paramarta@gmail.com
}

\begin{abstract}
Abstrak
Terapi untuk anak berkebutuhan khusus sangat penting juga konsep ruangan akan sangat berpengaruh pada hasil. Klinik tumbuh kembang di Bandung sudah sangat baik fasilitasnya tetapi karena kesadaran akan terapi dan pengobatannya juga ada metode dan fasilitas baru untuk terapinya. Sebagian besar klinik kurang memiliki konsep ruang terapi yang baik, seringkali hanya meletakkan semua fasilitas dalam satu ruangan tanpa mengurusi objek yang sudah ada. Penelitian ini akan membahas tentang ruang fisiotherapy dan bagaimana sebuah ruangan menjadi nyaman dan mengembangkan fokus pada anak. Metode proses penulisan ini adalah metode Kualitatif, yang penulis dapatkan dari wawancara dengan seorang dokter dan seorang ibu yang mempunyai anak berkebutuhan khusus berumur tiga tahun, penulis juga melakukan survey ke salah satu klinik yang bernama Klinik Kinder di Komplek Perumahan Holis Permai VII, di klinik ini mengadakan terapi satu lawan satu di ruangan berukuran $3 \times 4.7$ $\mathrm{M}^{2}$ dan studi pustaka tentang bagaimana bentuk ruangan yang nyaman untuk anak, terapis dan orang tua. Manfaat dari penelitian ini adalah penelitian ini dapat dilihat sebagai contoh konsep desain atau konsep desain ulang lainnya. Hasil akhir dari penelitian ini adalah adanya perubahan konsep karena banyaknya ornamen dan lain-lain.
\end{abstract}

Kata Kunci: Anak Berkebutuhan Khusus, Fisioterapi, Klinik Tumbuh Kembang.

\begin{abstract}
Therapy for children with special needs is very important as well as the concept of the room will greatly affect the results. The growth and development clinic in Bandung has very good facilities, but because of awareness of the therapy and its treatment, there are also new methods and facilities for its therapy. Most of the clinics lack the concept of a good therapy room, often only putting all facilities in one room without taking care of existing objects. This research will discuss about the physiotherapy room and how a room can be comfortable and develop a focus on children. This writing process method is a qualitative method, which the author got from an interview with a doctor and a mother who has a child with special needs aged three years, the author also conducted a survey to one of the clinics called the Kinder Clinic in Holis Permai VII Complex. One on one therapy in a room measuring $3 \times 4.7 \mathrm{M}^{2}$ and a literature study on how to form a comfortable room for children, therapists and parents. The benefit of this research is that it can be seen as an example of a design concept or other redesign concept. The final result of this research is a change in concept due to the many ornaments and others.
\end{abstract}

Keywords: Children with Special Needs, Physiotherapy, Growth and Development Clinic.

\section{A. PENDAHULUAN}

Belakangan ini kesadaran akan kebutuhan kesehatan anak berkebutuhan khusus semakin meningkat. Dengan kesadaran kebutuhan terapi bagi anak berkebutuhan khusus ini AKSELERASI: Jurnal Ilmiah Nasional Vol. 3 No. 1 Tahun 2021 
banyak sarana yang menyuguhkan jasa terapi bagi anak, salah satunya adalah klinik tumbuh kembang anak. Berbeda dengan jasa terapi lainnya klinik tumbuh kembang biasanya memiliki fasilitas yang lebih lengkap karena jasa yang ditawarkan lebih lengkap pula, seperti jasa dokter anak, jasa perawat dan jasa terapis. Dengan jasa yang lengkap kebutuhan ruang yang dibutuhkan juga menjadi lebih banyak lagi, seperti ruang terapi, ruang konsultasi dan ruangan lainnya.

Terapi bagi anak berkebutuhan khusus terdapat berbagai macam jenisnya seperti terapi motorik kasar dan halus, terapi okupasi, terapi wicara, terapi sensori, fisioterapi dan terapi lainnya. Terapi-terapi tersebut sangat membantu pertumbuhan anak agar lebih cepat berfungsi dengan normal seperti anak lainnya. Setiap terapi memiliki kebutuhan dan persiapan tersendiri, membutuhkan alat dan ruangan khusus sebagai sarana dan prasarana terlaksananya terapi yang maksimal.

Ruang fisioterapi adalah salah satu fasilitas yang disediakan pada klinik tumbuh kembang anak, ruang fisioterapi memiliki banyak fungsi ruang didalamnya. Terdapat empat bagian ruang yang biasanya terdapat di dalam ruang fisioterapi, area terapi berjalan, area terapi motoric kasar, area motoric halus dan area terapi pijat.

Pengguna utama didalam ruangan ini adalah terapis dan anak yang melakukan terapi. Dokter dan orang tua biasanya tidak masuk kedalam ruangan, namun situasi ini tergantung pada kebijakan terapis atau dokter. Karena jika orangtua menemani anak akan lebih sulit anak terfokus pada terapinya.

Objek penelitian kali ini adalah ruang fisioterapi bagi anak usia satu sampai lima tahun, kebutuhan anak anak usai satu sampai lima tahun cukup signifikan karena aktifitas yang dilakukan dan di terapakan dapat diarahkan cukup mudah. Pemasalahan utama pada anak usai satu sampai lima tahun adalah cara membuat anak tersebut fokus pada terapinya, kebanyakan anak sulit untuk fokus saat terapi berlangsung.

Kebanyakan klinik tumbuh tembang memiliki terlalu banyak aktifitas dan fasilitas dalam satu ruangan yang mencolok satu dan lainnya, seperti banyaknya mainan alat alat yang tidak tersusun rapi dan lainnya Sehingga dibutuhkannya perencanaan maksimal pada ruang fisioterapi, agar fungsi ruang dan terapinya menghasilkan hasil yang maksimal.

Istilah berkebutuhan khusus secara eksplisit ditujukan kepada anak yang dianggap mempunyai kelainan penyimpangan dari kondisi rata-rata anak normal umumnya, dalam hal fisik, mental maupun karakteristik perilaku sosialnya (Tamura, 2008).

Menurut kamus lengkap psikologi, terapi adalah suatu perlakuan dan pengobatan yang ditujukan kepada penyembuhan suatu kondisi patologis (pengetahuan tentang penyakit atau gangguan). Terapi juga dapat diartikan sebagai suatu jenis pengobatan penyakit dengan kekuatan batin atau rohani, bukan pengobatan dengan obat-obatan (Chaplin, 2006).

Salah satu terapi yang bisa dilakukan adalah fisioterapi. Fisioterapi adalah suatu terapi awal yang diperlukan oleh anak tuna grahita dikarenakan tuna grahita terlahir dengan tonus yang lemah, dengan terapi awal ini berguna untuk menguatkan otot-otot mereka sehingga kelemahannya dapat di atasi dengan latihan-latihan penguatan otot (Tamura, 2008).

Proses fisioterapi pada pasien adalah siklus kontinyu dan bersifat dinamis yang dilakukan oleh fisioterapis yang memiliki kompetensi yang dibutuhkan, diintergrasikan dan dikoordinasikan dengan pelayanan lain yang terkait melalui rekam medik, sistem informasi dan sistem komunikasi yang efektif (Prawira, 2013). 
Di Indonesia, dalam sebuah penelitian pada seratus sepuluh wilayah puskesmas di Pulau Jawa pada tahun 1987 memperoleh data 13\%, balita berpotensi mengalami keterlambatan perkembangan. Pada tahun 1998, di daerah kumuh perkotaan Bandung ditemukan $28,5 \%$ balita mengalami keterlambatan perkembangan (Suwarba, Widodo, \& Handryastuti, 2017).

Penanganan keterlambatan perkembangan salah satunya dapat dilakukan dengan cara melakukan fisioterapi. Pada kasus lambat kembang, fisioterapi bertujuan untuk membangkitkan sumber daya tahan tubuh alami, memperkuat memori bermotor genetik, mendukung fungsi koheren sensorik dan motorik sistem, menangani gangguan sensoris motor, menghambat gerakan abnormal, mengajarkan gerakan normal dengan merangsang titik kunci gerak, dan menekankan peningkatan gerak otomatis yang benar (Halimah, 2018).

Pada kasus keterlambatan perkembangan anak satu sampai lima tahun di Pulau Jawa mengalami peningkatan sebesar $15,5 \%$ dalam sebelas tahun. Kenaikan bukan saja berdasarkan Kesehatan anak yang terkena namun banyaknya juga orangtua yang menyadari bahwa pemeriksaan pada anak usia dini sangat penting untuk diperhatikan (Nur'aeni, 2019).

\section{B. TINJAUAN PUSTAKA}

\section{Standar Warna pada Ruangan}

Warna-warna yang mendukung kebutuhan anak dalam sebuah ruang seperti tersebut di atas, agar program kegiatan dapat berjalan dengan baik dan perkembangan anak optimal. Warna-warna yang dibutuhkan untuk menunjang perkembangan tersebut di atas adalah warna yang dapat memberikan suasana aman, hangat, nyaman, bebas dan rangsang. Warna-warna pastel dengan intensitas yang berbeda-beda dapat menunjang suasana ruang ruang tersebut di atas. Warna pastel aman dalam arti warna tidak menyilaukan, membuat mata cepat lelah, menyenangkan, tidak menakutkan dalam arti warna dapat memotivasi anak untuk beraktifitas, bergembira dan kreatif (Sari, 2004).

\section{Standar Bentuk pada Ruangan}

Sudut yang tajam sangat tidak dianjurkan dalam mendesain furnitur khusus untuk anak. Sangat baik untuk mendesain yang semua modulnya rounded dan menghindari sudut tajam, agar aman untuk anak (Delima, 2016). Bentuk yang digunakan juga harus menjadi edukasi bagi anak anak. Selain berpengaruh pada anak bentuk juga berpengaruh pada ruangan, luas dan tidaknya ruangan secara tidak langsung dipengaruhi oleh bentuk furnitur. Bentuk yang rumit membuat ruangan menjadi sempit.

\section{Standar Material pada Ruangan}

Aspek teknis, estetisdalamdesain mebelserta terkait dengan bahan, struktur dan konstruksi desain mebel berbahan kayu dan kayu lapis sebagaimana diuraikan oleh (Marizar, t.t.), (Jamaluddin, t.t.) sebagai dasar dalam penciptaan seni dalam wujud desain mebel untuk anak usia dini. Ergonomi aspek antropometri merujuk pada (Panero \& Martin; Zelnik \& Chiara 1992) khususnya untuk ukuran dibawah usia lima tahun. State of the art dari peenelitian ini, aspek estetis sebagai dasar pijakan desain furnitur bagi anak balita, namun juga faktor keamanan dalampenggunaan produk melalui soft finishing. Finishing produk melalui pelapis yang empuk dan lembut sehingga aman bagi anak-anak. Beberapa bahan 
ARTIKEL

yang memungkinkan untuk diaplikasikan dimana bahan utamanya dengan kayu selanjutnya pelapis dan penutup dapat dengan bahan busa, kain, karet, kulit. Road map penelitian terkait dengan anak-anak dan permainan adalah sebagai berikut (Sumarno, 2019).

\section{METODE}

Penelitian ini menggunakan metode kualitatif, dengan pengumpulan data melalui studi literatur, wawancara, dan survei lapangan. Survey dilakukan di sebuah klinik di Kota Bandung yang bernama klinik Kinder. Dilakukan untuk mengetahui kondisi yang terjadi di lapangan, dan menjadi acuan untuk penelitian lebih lanjut. Setelah pengumpulan data dilakukan maka selanjutnya adalah menganalisis masalah yang terdapat di ruang terapi anak berkebutuhan khusus klinik tumbuh kembang tersebut. Analisis segala macam permasalahan yang di dapat yang akan sangat berguna dalam proses perancangan interior ruang terapi nantinya.

Konsep merupakan bagian penting dalam perancangan sebuah interior, karena dengan konsep yang ditentukan maka perancangan sebuah interior akan lebih terarah dan matang. Oleh karena itu perancangan interior selanjutnya adalah tahap pembuatan konsep, yaitu dimulai dari pembuatan layout. Layout dibuat berdasarkan kebutuhan aktivitas yang disesuaikan dengan data-data yang telah didapatkan disertai dengan konsep material, warna dan bentuk yang digunakan pada ruang terapi yang baru. Setelah pengerjaan gambar kerja selesai, maka untuk realisasi perancangan dapat dilanjutkan dengan pembuatan 3D dari ruang khusus yang telah ditentukan. Pembuatan 3D ini akan sangat membantu dalam perancangan karena dapat dilihat langsng pemilihan material dan warna dari desain yang telah ditentukan.

\section{HASIL DAN PEMBAHASAN}

\section{Kondisi}

Pada ruang fisioterapi banyak sekali hal yang harus dilakukan sehingga untuk mendukung kegiatan fisioterapi tersebut banyak kebutuhan-kebutuhan khusus yang harus terpenuhi, fasilitas yang disediakan juga harus dapat memenuhi standar kesehatan yang baik. Kebanyakan ruang fisioterapi menyatukan banyak jenis terapi pada satu ruangan agar pelaksaan terapi berjalan lebih efisien ketika melakukan lebih dari satu terapi.

Berdasarkan wawancara dari salah satu narasumber, Biasanya seorang anak bisa melakukan satu atau dua terapi dalam satu pertemuan, terapi dilakukan sekitar satu hingga dua jam tergantung kondisi anak yang menjalani terapi. Fisioterapi biasa di lakukan oleh satu terapis untuk satu anak, karena terapi ini membutuhkan pengawasan yang maksimal, terapispun terkadang tidak akan berubah selama anak membutuhkan terapi. Kebanyakan anak akan terus menjalani terapi hingga ia tubuh dewasa, kecuali anak tersebut hanya mengalami cedera biasanya hanya sampai cedera pada area tersebut sembuh. Bedasarkan narasumber kebanyakan orangtua menegtahui anaknya membutuhkan fisioterapi pada usia enam hingga sembilan bulan bahkan ada yang saat berumur tiga tahun baru menyadari kebutuhan fisioterapi bagi anaknya. Sehingga penanganan untuk anak-anak akan sangat beragam. Berdasarkan umur, sifat, emosi dan lainnya.

Namun bedasarkan hasil wawancara yang terpenting adalah cara membuat anak-anak bisa fokus pada terapinya. Terkadang anak sangat sulit terfokus pada terapi, banyak factor yang menyebabkan anak tidak bisa fokus pada terapinya, seperti mood anak hari itu, 
terdistract oleh barang tertentu dan lainya. Banyaknnya barang yang digunakan terkadang menjadi pengalih perhatian anak jika tidak di organisir dengan baik.

\section{Konsep}

Konsep secara keseluruhan yang digunakan sangat simple, karena banyaknya barang yang dibutuhkan pada ruangan ini sangat penting untuk tidak banyak menggunakan ornament ornamen yang tidak penting, cukup menggunakan ornament dan funitur sederhana agar ruang terlihat luas, nyaman dan yang terpenting tidak mengalihkan perhatian anak dari proses terapinya. Ruangan yang digunakan harus multifungsi agar semua proses terapi dapat dilakukan hanya pada satu ruangan saja. Terapi yang di lakukan pada satu ruangan bisa mempersingkat waktu dan lebih efisien dari pada berpindah karena mungkin saja saat berpindah mood anak akan berubah dan menggangu proses terapinya sendiri.

\section{Konsep Bentuk}

Bentuk yang dipilih akan sangat berpengaruh pada kondisi ruangan, karena tujuan utamanya adalah efisiensi ruangan sehingga bentuk yang digunakan adalah bentuk bentuk sederhana seperti lingkaran, persegi dan segitiga karena pola yang rumit kurang baik bagi anak anak usia satu sampai lima tahun, terutama anak anak berkebutuhan khusus yang sulit berkonsentrasi pada satu hal. Bentuk bentuk sederhana membantu anak untuk lebih berkonsentrasi pada satu hal.

Bentuk bentuk yang rumit akan sangat dihindari, selain karena konsentrasi anak bentuk sederhana juga membantu ruangan agar terlhat lebih luas karena dibutuhkannya area yang cukup luas untuk melakukan fisioterapi. Bentuk yang miliki ujung tajam juga sangat diperhatikan karena keselamatan anak cukup harus diperhatiakan. Banyak aktivitas berjalan merangkak, melompat dan memanjat sehingga anak akan banyak bergerak, ujung ujung benda tajam akan sangat berbahaya jika digunakan.

Bentuk dengan ujung tajam seperti segitiga dan persegi digunakna pada barang tertentu yang tentunya jauh dari jangkauan anak-anak.

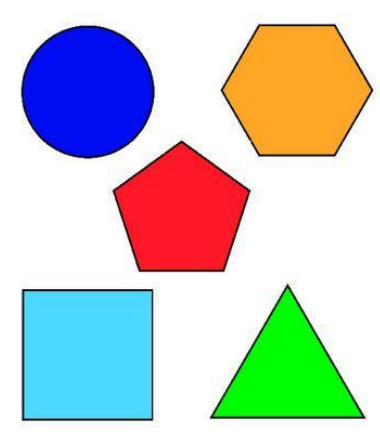

Gambar 1 Basic Shapes

\section{Konsep Warna}

Warna yang digunakan adalah warna warna pastel sebagai warna warna utamanya, alasan penggunaan warna pastel adalah warna pastel lebih menenangkan dan cocok dibandingkan warna lainnya, kombinasi ini juga membuat ruangan lebih bervariatif namun 
simple. Warna pastel menjadi warna basic yang harus di rangsang oleh otak anak sejak kecil, sehingga warna warna ini juga kurang lebih membantu proses terapi yang di lakukan.

Warna warna lain tetap digunakan seperti warna netral coklat, hitam dan putih pada area tertentu saja. Untuk menyeimbangkan suasana yang di bangun oleh ruangan.

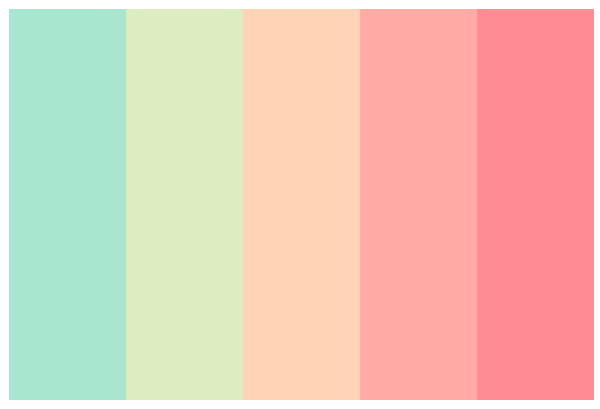

Gambar 2. Warna Pastel

\section{Material}

Material yang empuk seperti busa digunakan pada banyak area selain untuk alasan keamanan anak saat melakukan terapi, material yang empuk juga membuat anak lebih nyaman saat berada di ruangan tersebut. Material kayu solid digunakan pada beberapa fasilitas terapi seperti papan jalan, dan tangga terapi dengan tambahan pengaman yang empuk pada beberapa bagian. Material kayu tidak banyak digunakan karena keras dan mudah terbakar. Furnitur lain menggunakan multiplek dengan finishing hpl.

Material sebisa mungkin tidak mengeluarkan bebauan yang menyengat atau mengandung bahan bahan kimia yang berbahaya, karena anak-anak cukup sulit di tebak, bisa saja menjilat atau memakn material yang ada. Material khusus digunakan untuk Latihan sensori anak pada satu bagian ruangan, namun tetap dengan memerhatikan keamanan dan efisiensi dari material tersebut.

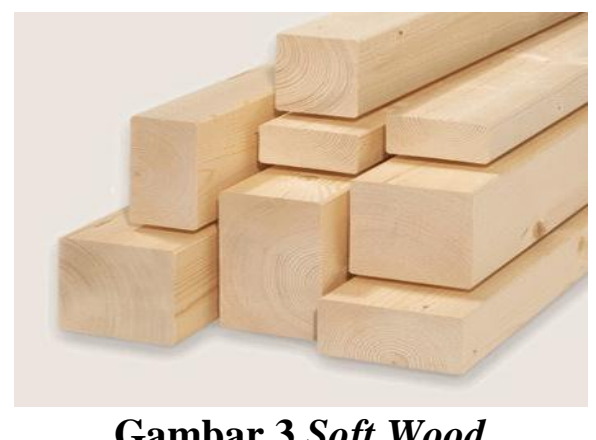

Gambar 3 Soft Wood

\section{Organisasi}

Ruang diorganisasi berdasarkan kegiatan dasar dari fisioterapi. Fisioterapi biasanya dibagi menjadi beberapa kegiatan dasar yaitu, latihan berjalan, latihan motoric kasar, latiahn motoric halus dan terapi pijat. Maka ruangan dibagi menjadi empat kegiatan dasar tersebut.

Pada area latihan atau terapi berjalan terdapat dua fasilitas utama yaitu papan berjalan dan parallel bar, latihan motoric kasar terdapat wall climbing dan tali mengantung, sedangkan area latihan motoric halus terdapat meja dan kursi untuk terapi di atas meja, dan alat alat 
terapi sensori, pada area terapi pjat terdapat matras dan area luas difasilitasi dengan storage untuk alat alat pijat yang digunakan

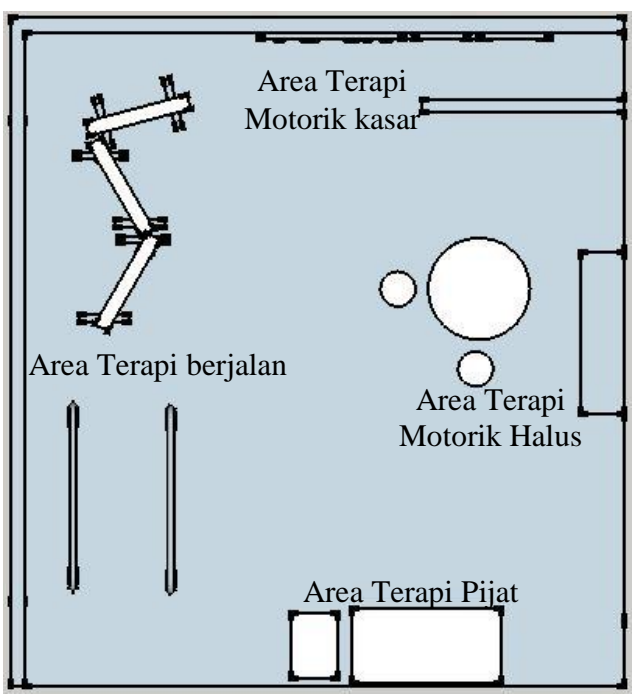

Gambar 4. Layout

\section{E. KESIMPULAN}

Warna yang digunakan adalah warna-warna pastel yang dapat membuat anak lebih focus atau tidak mengalihkan perhatian anak. Warna pastel juga baik baik pertumbuhan anak 1-5 tahun. Bentuk yang digunakan adalah bentuk yang paling sederhana, dengan menggunakan basic shapes seperti lingkaran segitiga dan persegi namun tetap di perhatiakan untuk menjauhkan bagian tajam dari jangkauan anak-anak. Material yang digunakan adalah material softwood dengan finishing hpl yang aman bagi anak-anak. Organisasi ruang dibagi menjadi 4 kegiatan utama yaitu, latihan berjalan, latihan motoric kasar, latiahn motoric halus dan terapi pijat. Dengan fasilitas fasilitas pendukung lainnya.

\section{UCAPAN TERIMAKASIH}

Penulis ingin menyampaikan terima kasih kepada orang tua dan Program Studi Desain Interior Telkom University.

\section{DAFTAR PUSTAKA}

Chaplin, J. P. (2006). Kamus Lengkap Psikologi. Jakarta: Raja Grafindo Persada.

Putri, R. D. C. (2016). Desain Furniture Set Taman Kanak-Kanak Sebagai Sarana Pendukung Pembelajaran Yang Interaktif (Doctoral Dissertation, Institut Teknologi Sepuluh Nopember).

Nur'aeni, R. (2019). Animasi Pembelajaran untuk Fisioterapi pada Anak Global Development Delay (Studi Kasus di Unit Instalasi Rehabilitasi Medik, RS. Sardjito Yogyakarta).

Prawira, F. R. (2013). Penatalaksanaan Fisioterapi. עלון הנוטע, 66, 37-39.

Sari, M. S. (2004). Peran Warna Interior Terhadap Perkembangan dan Pendidikan Anak di Taman Kanak-Kanak. Dimensi Interior, 2(1), 22-36. 
ARTIKEL

Sumarno. (2019). Soft Finishing (Desain Furnitur Untuk Anak Usia Dini).

Tamura, H. (2008). Terapi Psikoreligius dan Narkoba. Journal of Chemical Information and Modeling, 53(9), 287. https://doi.org/10.1017/CBO9781107415324.004

Suwarba, I. G. N., Widodo, D. P., \& Handryastuti, R. S. (2017). Profil Klinis dan Etiologi Pasien Keterlambatan Perkembangan Global di Rumah Sakit Cipto Mangunkusumo Jakarta. Sari Pediatri, 10(4), 255. https://doi.org/10.14238/sp10.4.2008.255-61 